\title{
¿EL CORTESANO O LOS CORTESANOS? ALGUNOS EJEMPLOS LITERARIOS EN EL MADRID DEL SIGLO XVII
}

\author{
María Soledad Arredondo \\ (Universidad Complutense de Madrid) \\ msarredo@,filol.ucm.es
}

\section{RESUMEN}

Análisis del cortesano y de su evolución desde el modelo renacentista de Castiglione-Boscán hasta el personaje barroco. Se muestran los cambios, no solo por el transcurso del tiempo, sino también por los géneros literarios que se refieren al personaje (novela picaresca, novela cortesana, libros costumbristas, literatura encomiástica, tratados, etc.), y por las cortes que describen. Se parte de ejemplos del siglo XVI para llegar a la corte madrileña del XVII, según Guía y avisos de forasteros que vienen a la corte, Los Peligros de Madrid y El día de fiesta por la mañana y por la tarde para desembocar en un libro "histórico-político": Solo Madrid es corte y el cortesano en Madrid, donde las características didácticas se acentúan. Se concluye que la obra de Alonso Núñez de Castro responde a los dos propósitos del título: la descripción y elogio de la Corte de Madrid (I), y las normas para el cortesano que quiera establecerse en ella (II, III, IV).

PALABRAS CLAVE: cortesano; literatura cortesana; Renacimiento; Barrroco; Madrid.

\section{THE COURTESAN OR THE COURTESANS? SOME LITERARY EXAMPLES IN SEVENTEENTH CENTURY MADRID}

\begin{abstract}
Analysis of the courtier and its evolution from the Renaissance model of Castiglione-Boscán to the baroque character. The changes are shown, not only by the passage of time, but also by the literary genres that refer to this character (picaresque novel, court novel, costumbrist books, commendable literature, treatises, etc.) and by the courts they describe. It starts with examples from the 16th century to reach the Madrid court of the 17th century, according the Guia y avisos de forasteros que vienen a la corte, Los Peligros de Madrid, El dia de fiesta por la mañana y por la tarde, and leading to a "historical-political" book: Solo Madrid es corte y el cortesano en Madrid, where the didactic characteristics are accentuated. It is concluded that the work of Alonso Núñez de Castro responds to both purposes of the title: the description and praise of the Court
\end{abstract}


of Madrid (I), and the rules for the courtier who wants to establish himself in it (II, III, IV).

KEY WORDS: courtier; courtly literature; Renaissance; Baroque; Madrid.

En este trabajo pretendo mostrar ejemplos sobre las diversas figuras del cortesano, según aparece en algunas obras en prosa del siglo XVII (tratados, libros de avisos y textos costumbristas), para desembocar en Solo Madrid es corte, como se designó el Congreso Internacional celebrado en Madrid, diciembre de 2020, es decir: Solo Madrid es corte y El cortesano en Madrid (1658), del cronista Alonso Núñez de Castro, también llamado libro bistórico político.

Empezando por la terminología, como han hecho notar quienes me han precedido en la ya extensa bibliografía sobre la cuestión ${ }^{1}$, el Tesoro de la lengua castellana o española (1611), de Sebastián de Covarrubias, define la Corte como «el lugar donde reside el Rey»; y al cortesano como «...el que sigue la corte, sirviendo al Rey, y porque se presume que los tales son muy discretos y avisados llamamos cortesanos a los que tienen bueno y hidalgo término y honrado trato...» (p. 243).

Destaco de esta definición el tono positivo que se aprecia en la adjetivación: los cortesanos son «discretos y avisados», y tienen «honrado trato». Por cierto, no así en femenino, como era habitual en la época, porque la cortesana era la «mujer libre que en la guerra seguía la cohorte... de allí les quedó el nombre de cortesanas a las que en la Corte viven licenciosamente...» (p. 243).

En el Diccionario de Autoridades (1726-1739), un siglo después, se precisa más, porque Corte es «la ciudad o villa donde reside de asiento el Rey o Príncipe soberano, y tiene sus consejos...». Y el cortesano, como adjetivo: «vale también entendido, avisado, atento y discreto»; y como sustantivo «el Palaciego, el que sigue y sirve al Rey en la corte...». Se apoya este Diccionario en la autoridad de Saavedra Fajardo en sus Empresas, (1640) para contraponer cortesanos y soldados: «las delicias, las galas y las riquezas son para los cortesanos: en los soldados despiertan la codicia del enemigo...» (Empresa 82).

En ambos diccionarios se parte del lugar donde se establece la Corte, para definir al cortesano que no es todo el que habita en ese lugar, sino el que sirve al Rey con algún título u oficio y también el que «sigue» la Corte, cuando ésta se desplaza.

Recordemos, sin embargo, que Lázaro de Tormes, por ejemplo, se ufana sarcásticamente de servir al rey, en el tratado séptimo, porque ha logrado un «oficio

${ }^{1}$ Ver el estudio ya clásico de José Deleito y Piñuela, Sólo Madrid es corte. La capital de dos mundos bajo Felipe IV (Madrid: Espasa - Calpe, 1953). Y para la evolución del concepto Antonio Álvarez Ossorio, "Corte y cortesanos en la Monarquía de España", en Educare il corpo, educare la parola. Nella tratatistica del Rinascimento, ed. G. Patrizi y Amedeo Quondam (Roma: Bulzoni, 1998), 297-365. 
real» $\gg^{2}$ aunque sea el más mísero, el de pregonero; y que los costumbristas barrocos se dirigen o apelan a los forasteros que siguen o llegan a la Corte con la sola intención de medrar.

Como ha estudiado Martínez Millán ${ }^{3}$ la Corte de la Monarquía Hispánica se componía de tres elementos: la Casa Real, los Consejos y Tribunales, y los cortesanos: «quienes elaboraron una conducta específica para conseguir sus propios intereses» (p. 17), con un comportamiento que fue evolucionando «... al margen de toda norma ética, y referencia religiosa, y orientado exclusivamente a conseguir el propio interés» (p. 59).

En efecto, si nos detenemos en la literatura del Siglo de Oro, el concepto de Corte evoluciona desde el refinamiento renacentista que nos traslada Juan Boscán en su traducción (1534) de El Cortesano (1528) de Castiglione, hasta el espacio urbano madrileño del XVII, escenario favorito de novelas y comedias. Sin embargo, una obra contemporánea de ese Cortesano tan admirado, el Menosprecio de corte y alabanza de aldea (1539) del cronista y predicador Fray Antonio de Guevara, ya lanzaba recriminaciones contra la corte y las envidias cortesanas. Estos dos brillantes ejemplos del siglo XVI, aunque son bien distintos, indican que no solo el correr del tiempo puede cambiar la visión positiva de corte y cortesanos por una negativa y censora (o hacer que ambas convivan), sino que las opiniones también dependen de la coyuntura personal de cada autor y del género literario ${ }^{4}$ en que se exprese.

$\mathrm{Y}$ son muchos los géneros y subgéneros literarios que se ubican en la corte madrileña del siglo XVII. Por mencionar solo algunos:

En primer lugar, la novela picaresca, un género eminentemente urbano desde la Salamanca de los orígenes del Lazarillo a la insigne Toledo, donde termina el libro diciendo que allí el Emperador celebró Cortes. A partir del sentido o exigencia no solo de urbe, sino de capitalidad ${ }^{5}$, aparecen Sevilla, Valladolid y Madrid como sedes

${ }^{2}$ La vida de Lazarillo de Tormes y de sus fortunas y adversidades, ed. Alberto Blecua (Madrid: Castalia, 1983): "Y con favor que tuve de amigos y señores, todos mis trabajos y fatigas hasta entonces pasados fueron pagados con alcanzar lo que procuré: que fue un oficio real, viendo que no hay nadie que medre sino los que le tienen" (pp. 172-173). Ver Fernando Lázaro Carreter, "El oficio real" en Lazarillo de Tormes en la picaresca (Barcelona: Ariel, 1983): El Lazarillo es "el testimonio de un desencanto, la ejemplificación de un ansia colectiva mediante un personaje, en último término grotesco, que rueda por un mundo cruel hacia el deshonor, y al que, sin embargo, no falta aliento para sumar su voz al coro de postulantes de honra" (pp. 183-184).

3 José Martínez Millán, "La corte de la Monarquía Hispánica”, Studia bistorica 28 (2006): 17-61.

4 Ver Amedeo Quondam, “Adiós a la corte: de nuevo Fray Antonio de Guevara y su Menosprecio”, en El discurso cortesano, ed. Eduardo Torres Corominas (Madrid: Polifemo, 2013), 72-77, y la "Introducción" de Torres Corominas que indica lo abigarrado del llamado "discurso cortesano", que incluye "tratados de cortesanía, libros de avisos, literatura anticortesana y, en general, textos de naturaleza diversa donde, [...] la cultura cortesana salta a la palestra para ser descrita, moldeada, descifrada o denostada..." (p.13).

${ }^{5}$ Ver José Antonio Maravall, La cultura del barroco (Barcelona: Ariel, 1986), 226-228, donde habla de una "cultura urbana", de las diferencias entre "la ciudad del siglo XV" y los grandes núcleos urbanos del XVII", donde se generan y consumen creaciones artísticas; y afirma "Cada novela picaresca va ligada a alguna o algunas ciudades" (p. 228). Por su parte, Florencio Sevilla, en la "Presentación" a su monumental edición de La novela picaresca española (Madrid: Castalia, 2001) IX-XI, destaca el contraste 
geográficas por las que pulula la picardía, siempre dispuesta a medrar en la Corte. Basta el ejemplo del libro tercero del Buscón, de Quevedo, que retrata las miserias y engaños de la capital y de los cortesanos. O el ejemplo picaresco, en femenino y madrileño, de Castillo Solórzano con La niña de los embustes. Teresa de Manzanares (1632), donde el engaño se expresa desde el título, aunque la carga crítica esté más edulcorada que en sus homónimos masculinos.

En segundo lugar, la novela corta, o novela cortesan ${ }^{6}{ }^{6}$ desde el estudio de Agustín González de Amezúa (1929), que utilizaba ciudades y ambientes cortesanos como marco para las novelas cortas de tema amoroso que siguieron a las Ejemplares (1613) cervantinas, como Las harpias en Madrid (1631), de Castillo Solórzano, o algunas de María de Zayas. Ese ambiente cortesano da cabida a personajes nobiliarios, a damas y pretendientes con sus respectivos criados, y a busconas con apariencia de dama que asaltan las bolsas de los incautos.

También el llamado costumbrismo ${ }^{7}$ del siglo XVII, como la Guía y avisos de forasteros que vienen a la corte (1620), de Antonio Liñán y Verdugo, Los Peligros de Madrid (1646), de Baptista Remiro de Navarra, El día de fiesta por la mañana y por la tarde (1654 y 1660), de Juan de Zabaleta, o Día y noche de Madrid (1663), de Francisco Santos. Estos títulos son una muestra de la narrativa heredera de la picaresca menor, que añade a la ficción y la burla ${ }^{8}$ un componente didáctico, a medio camino entre los libros de avisos ${ }^{9}$ y los tratados o manuales de educación. La etiqueta de "costumbrismo" sirve para agrupar textos muy diferentes, en los que se desdibujan las características formales de los libros de pícaros, empezando por la narración autobiográfica, pero manteniendo escenarios urbanos, tipología menor o vil en los protagonistas, y una temática basada en el hambre, el deshonor, las apariencias y la consecuente crítica social.

con los libros de pastores y el proceso evolutivo de los libros de pícaros en todos los aspectos de su poética. Para la corte de Madrid ver Enrique García Santo Tomás, Espacio urbano y creación literaria en el Madrid de Felipe IV (Madrid: Universidad de Navarra/Iberoamericana/Vervuert, 2004), y Juan Ramón Muñoz Sánchez, "La Corte, del mundo maravilla: la picaresca durante el reinado de Felipe IV", NRFH LXII, 2 (2014): 383-480.

${ }^{6}$ Ver Agustín González de Amezúa, Formación y elementos de la novela cortesana (Madrid: Tipografía de Archivos, 1929) y Pedro Ruiz, "Corta / cortesana. Apuntes a propósito de una denominación problemática para la narrativa barroca”, Lejana. Revista crítica de narrativa breve 7 (2014): 1-13.

${ }^{7}$ Ver para esta denominación el estudio ya clásico de Evaristo Correa Calderón, Costumbristas españoles

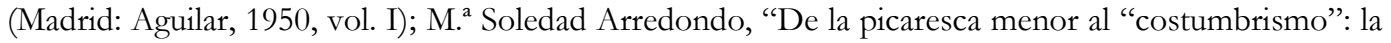
Guia y avisos de forasteros... y otros escarmientos", Edad de Oro XX (2001): 9-21; y David González Ramírez, "La disolución del marco narrativo en el origen del costumbrismo. De la Guía y avisos de forasteros a los días de fiesta de Zabaleta", Cuadernos de Filología Italiana, volumen extraordinario (2010): 8194.

${ }^{8}$ Remito al Seminario "Burla y engaño: actitudes sociales y representaciones literarias", celebrado en la Casa de Velázquez en 2001, y a mi comunicación en el mismo, cuya versión escrita fue: M. ${ }^{a}$ Soledad Arredondo, "El engaño cortesano en los relatos de la Guia y avisos de forasteros que vienen a la corte, de Liñán y Verdugo", en Siglos dorados. Homenaje a Augustin Redondo I, coord. Pierre Civil (Madrid: Castalia, 2004), 67-82.

${ }^{9}$ Ver M $\mathrm{M}^{\mathrm{a}}$ Soledad Arredondo, “Avisos sobre la capital del orbe en 1646: Los Peligros de Madrid",

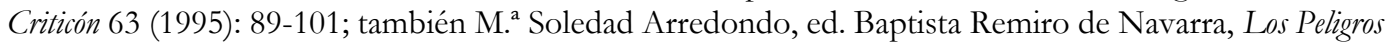
de Madrid (Madrid: Castalia/Comunidad de Madrid, 1996), 11-39. En adelante cito la obra por esta edición. 
Así, desde las tempranas innovaciones formales de Salas Barbadillo, por ejemplo, en La sabia Flora, malsabidilla $(1621)^{10}$; a las descripciones satíricas que realiza Remiro de Navarra de espacios madrileños (El Prado, la calle Mayor, el Manzanares y sus baños) y de personajes femeninos cortesanos (cortesanas, ahora sí) que protagonizan los diez capítulos de Los Peligros de Madrid); hasta el sermoneo generalizador de Zabaleta en sus Días, bien de tipos (el galán, el enamorado, el avariento), bien de costumbres (las visitas y el estrado, la romería de Santiago el Verde, la fiesta del Trapillo, la corte madrileña parece el lugar por el que transitan la pereza, la vanidad y la mentira. Los autores de esta prosa advierten y aconsejan a sus lectores para que eviten la Corte o, si precisan frecuentarla, que vayan prevenidos; y para que el aviso sea eficaz lo envuelven en chistes, y lo culminan con máximas pesimistas para escarmiento ${ }^{11}$ de incautos.

No hay que olvidar que El Cortesano de Castiglione proponía un modelo de cortesano exquisito en un ambiente nobiliario, mientras que estos libros de avisos del XVII, aunque eran moralizadores, también contenían novelas y anécdotas amenas, protagonizadas por quienes llegaban a la corte y pretendían asentarse en ella. Por ejemplo, la edición de la Guía y avisos de forasteros de 1621, se titula Avisos de los peligros que hay en la vida de corte, novelas morales y ejemplares escarmientos, y solo en la tasa y en el privilegio hallamos el título que hoy conocemos: Guia y avisos de forasteros ${ }^{12}$. Sin embargo, en la edición digitalizada por la Biblioteca Nacional de España, la de 1753, ya aparece La Guía con ese título, pero con el subtítulo «historia de mucha diversión, gusto y apacible entretenimiento...», que modifica sustancialmente el sentido de la lectura, sin duda para atraer a un mayor número de lectores.

Finalmente, en cuarto lugar, la literatura áulica y encomiástica, en general, especialmente la concebida en torno al Rey, de la que destaco tres títulos:

-una peculiar biografía: el libro coordinado por doña Ana de Castro Egas, La eternidad del rey don Filipe tercero nuestro señor (1629), que es una biografía de Felipe III en la que ocupan más espacio los paratextos que el propio cuerpo de la obra. Y es que en ella participan, además de muchos nobles y títulos, grandes ingenios de la corte (Bocángel, Pérez de Montalbán, Lope de Vega, Pellicer, etc.), que alaban en los preliminares al Rey piadoso, a la autora de la obra o a ambos, sin olvidar un notable y elogioso epílogo en prosa de Quevedo ${ }^{13}$.

${ }^{10}$ Ver para ello M. ${ }^{a}$ Soledad Arredondo, "De La Gitanilla a La sabia Flora malsabidilla. El género, el personaje y el matrimonio", Edad de Oro XXXIII (2014): 163-177.

11 Remito a mi artículo: M. a Soledad Arredondo, "De la picaresca menor al "costumbrismo": la Guía y avisos de forasteros... y otros escarmientos", Edad de Oro XX (2001): 9-21.

${ }^{12}$ En la biblioteca Histórica Marqués de Valdecilla (UCM) se halla un ejemplar de la primera tirada (Madrid: Viuda de Alonso Martin, 1620), que fue retirada por erratas en la portada, y cuyo título es: Guía y avisos de forasteros, a donde se les enseña a huir de los peligros que hay en la vida de Corte, y debaxo de novelas morales, y exemplares escarmientos, se les avisa y advierte de cómo acudirán a sus negocios cuerdamente.

${ }^{13}$ Ver Carmen Peraita, "Apacible brevedad de los renglones, abreviada vida de monarcas: Ana de Castro Egas, Francisco de Quevedo y la escritura del panegírico regio", La Perinola 9 (2005): 151-170. 
- una recopilación poética excepcional por el número y la brillantez de los autores: el Anfiteatro de Felipe el Grande $(1631)^{14}$, que contiene los elogios «que los mayores ingenios de España» (Lope, Quevedo, Pellicer, Saavedra Fajardo...) dedicaron al Rey en la fiesta agonal del 13 de octubre de 1631. Se trataba de un espectáculo de fieras organizado por Olivares, celebrado en Madrid con motivo del cumpleaños del príncipe heredero, y en aquella ocasión Felipe IV disparó un arcabuzazo certero contra un toro, lo que fue muy alabado. Los poemas laudatorios al respecto fueron rápidamente recopilados por el cronista José Pellicer de Tovar, que editó el Anfiteatro, con aprobación de Lope, bajo la protección del Conde-Duque de Olivares, y el mismo Pellicer escribió la «Noticia previa en prosa», dedicada a la hermana del Rey, Doña María, ya reina de Hungría y ausente en el espectáculo. A mi entender no cabe publicación más cortesana. Además, ésta emanaba desde el epicentro de la corte, en la Plaza del Parque, cerca de la Plaza Mayor de Madrid, que había sufrido recientemente un incendio.

- y también cierta poesía académica sobre algún acontecimiento concreto, como la Academia burlesca que se bizo en Buen Retiro a la Majestad de Filipo IV el Grande año de $1637^{15}$, en la que participaron grandes poetas de la Corte para dar lustre a los festejos que celebraban la entrada en Madrid de la princesa de Cariñán, la proclamación del cuñado de Felipe IV como Rey de Romanos... y, de paso, para exhibir el poderío de la corte madrileña y la brillantez del Palacio del Buen Retiro.

Un ejemplo curioso que muestra la importancia cortesana de dicho acontecimiento, y las posibilidades de promoción que conllevaba, es el Contexto de las reales fiestas que se bicieron en el palacio del Buen Retiro $(1637)^{16}$, de la dramaturga y relatora de sucesos Ana Caro de Mallén. La autora relata el festejo por medio de tres discursos, con una interesante dedicatoria en cada uno de ellos, por lo influyentes que son los respectivos dedicatarios: la primera (en prosa) se dirige a doña Agustina Espínola y Eraso, esposa del poderoso banquero Carlos Stratta, que financió buena parte de la fiesta; la segunda al Conde-Duque, protector y mecenas de la autora; y la tercera (en romance) a la «muy noble, Ilustre, Insigne, Leal y coronada villa de Madrid» (fol. 30), exaltando su generosidad en la organización del festejo: «por su esplendor y magnificencia al organizar las fiestas». Por ello «Para aplaudir estas dichas / Toda Madrid se alborota /Toda España se previene, / Todo el Orbe se convoca...» (fol. 32).

${ }^{14}$ Ver la edición de Antonio Pérez Gómez (Cieza: Ediciones Conmemorativas, 1974), y los estudios de Mercedes Blanco, "Un monumento poético en torno a la imagen de Felipe IV: el Anfiteatro de Felipe el Grande", en Los poderes de la imagen (Lille: Université de Lille 3, 1998) 107-114; Francisco Javier Díez de Revenga, "Saavedra Fajardo en el Anfiteatro de Felipe el Grande", Monteagudo 86 (1984): 69-74; José Jaime García Bernal, "De Felipe el Grande al Rey Pacífico. Discursos festivos y funerales durante el reinado de Felipe IV”, Obradoiro de Historia Moderna 20 (2011): 73-104; y Christine Orobitg, "Anécdota cinegética y construcción del personaje histórico en el Anfiteatro de Felipe IV el Grande (1631), de José Pellicer", en José Enrique Duarte e Isabel Ibáñez, eds., El hombre histórico y su puesta en discurso en el Siglo de Oro (New York: Idea, 2015), 139-153.

${ }^{15}$ Ver la edición de $\mathrm{M}^{\mathrm{a}}$ Teresa Julio (Madrid: Iberoamericana/Vervuert, 2007).

${ }^{16}$ Ver la edición de Antonio Pérez Gómez (Valencia: Tipografía Moderna, 1951). 
En los tres casos citados quienes componen y participan en estos libros son cortesanos o aspiran a serlo; y viven en la Corte, cerca del Rey, del valido o de personajes poderosos e influyentes a los que admiran y quieren agradar, siguiendo lo que Pellicer y Tovar llama en un aviso de 1639 «la carrera de la lisonja» ${ }^{17}$.

Pero, además, hay cortesanos en las cortes itinerantes, como ha estudiado Fernández Gracia ${ }^{18}$ a partir del Diario del viaje a Alemania, de don Juan de Palafox y Mendoza, que acompañó como capellán y limosnero a la infanta doña María en 1631, cuando iba a contraer matrimonio en Viena. El Diario... de Palafox ${ }^{19}$ no solo muestra el largo y difícil recorrido, junto a interesantes observaciones políticas, sino también las actitudes del séquito nobiliario de la Infanta, a veces movidas por ambición o interés. Este recorrido por una Europa en guerra, desde 1629 a 1631, fue una oportunidad que el joven Palafox no desaprovechó para asentarse en la corte madrileña como hechura de Olivares, y para el que contó con el beneplácito de la Infanta María, que supo apreciar su condición de «espiritual y cortesano», según recoge la biografía del Padre González Rosende ${ }^{20}$.

Y hay también cortes ocasionales, como la que se refleja en La corte en el valle, una comedia de circunstancias compuesta por Sebastián de Villaviciosa, Juan de Matos Fragoso y Francisco Avellaneda. Esta pieza dramática se inserta en las fiestas organizadas en Valladolid para agasajar a Felipe IV cuando regresaba de Irún, tras la jornada de 1660, cuando se celebró la boda de la infanta $\mathrm{M}^{\mathrm{a}}$ Teresa con Luis XIV y se firmó la Paz de los Pirineos. Se trata de una obra curiosa, que mezcla personajes alegóricos con ambientes y personajes bucólicos y con vasallos-pastores. La peculiaridad de esa Corte es que aparecen en ella el propio Rey (convertido en el mayoral Fileno), don Luis de Haro, y también la reina Mariana y la Infanta Reina $\mathrm{M}^{\mathrm{a}}$ Teresa $^{21}$, ausentes en esa corte bucólica, pero bien evocadas con nombres poéticos: Amarinda y Tirse. Ambas aparecen adornadas con los atributos habituales de belleza y discreción: la primera se halla en la corte madrileña, que Felipe IV añora tras el fatigoso viaje, y la segunda está llegando a la corte parisina, convertida en símbolo de paz y expectativa de fecundidad como «madre de un delfín» (p. 473).

17 Avisos I, ed. Jean-Claude Chevalier y Lucien Claire (Paris: Éditions Hispaniques, 2002), 47.

${ }^{18}$ Ricardo Fernández Gracia, "Una corte itinerante por tierras europeas 1629-1631. De Madrid a Viena con la infanta doña María, bajo la mirada de don Juan de Palafox", en Visiones de un imperio en fiesta, dir. Inmaculada Rodríguez Moya y Víctor Mínguez Cornelles (Madrid: Fundación Carlos de Amberes, 2016), 309-339.

${ }^{19}$ Ver M. ${ }^{a}$ Soledad Arredondo, "Diálogo, diario, historia, juicio, dictamen: géneros y estilo en la prosa política de Juan de Palafox y Mendoza", Revista Internacional d'Humanitats 30 jan (2014).

${ }^{20}$ Ver Antonio González de Rosende, Vida del Ilustrísimo y excelentísimo señor Don Juan de Palafox y Mendoza, en Obras completas, tomo XIII, libro I, cap. IX (Madrid, Imprenta de Gabriel Ramírez, 1762), 46. Ver también M. a Soledad Arredondo, "Juan de Palafox y Mendoza: la vida de un consejero, obispo, virrey... y escritor" en De la vida a la fantasía (Madrid: Visor en prensa).

${ }^{21}$ Me he referido a ello en M. . Soledad Arredondo, "M. a Teresa de Austria y la Paz de los Pirineos", en Mujeres en la Corte de los Austrias. Una red social, cultural, religiosa y politica, ed. Ma Leticia Sánchez Hernández (Madrid: Polifemo, 2019), 450-478, especialmente 472-473, y también en "Una relación total: el viaje, las fiestas, la boda y la Paz de los Pirineos en el Viaje del rey nuestro señor don Felipe IV a la frontera de Francia (1667), de Leonardo del Castillo", Homenaje a Jean-Pierre Étienvre en prensa. 
Estas obras literarias crean espacios cortesanos dependiendo de las circunstancias, y según sean esas cortes así serán los cortesanos; así parece darlo a entender el título de Núñez de Castro - una sola corte y un cortesano para ella - sin que haya un modelo unánimemente admirado equiparable al de Castiglione ${ }^{22}$. En el siglo XVII el tipo humano y el personaje literario subsiguiente pueden evolucionar del cortesano al discreto ${ }^{23}$, por referirme tan solo a uno de los modelos trazados por Gracián (1646): un autor tan admirado en Europa que su Oráculo manual fue traducido por Amelot de la Houssaie ${ }^{24}$ y muy oportunamente dedicado a Luis XIV en 1684, pero titulándolo L'bomme de cour, como si el arte de prudencia de Gracián fuera la característica fundamental del hombre de corte a la francesa. Ese personaje cortesano convive con otras figuras literarias de interés en su tiempo, como el príncipe político cristiano de Saavedra, en las Empresas (1640), o el Hombre Práctico (1686) de Francisco Gutiérrez de los Ríos. E incluso pueden mezclarse varias actividades en la persona del cortesano, como ocurría con los hermanos Argensola, «cortesanos, cronistas y poetas...», o con Góngora y Quevedo, «literatos y cortesanos» ${ }^{25}$. Así lo intuía Lope de Vega, que desconfiaba de los que llamaba «pájaros nuevos», como José Pellicer de Tovar, aquellos que intentaban medrar en la corte y le amargaron sus años de senectute ${ }^{26}$.

Toda esta amalgama de obras y otras de género impreciso o mixto ${ }^{27}$, me permiten llegar a Solo Madrid es corte y el cortesano en Madrid, del que paso a ocuparme a

22 Ver la Introducción de Amedeo Quondam a la edición de El Cortesano (Milan: Garzanti, 1987). Como ha afirmado Francesco Benigno, "Corte y anti-corte en la literatura política barroca", en La corte del Barroco. Textos literarios, avisos, manuales de corte, etiqueta y oratoria, coord. Antonio Rey Hazas, Mariano de la Campa Gutiérrez y Esther Gómez Pablo (Madrid: Polifemo, 2016), 27-52, 27, esa corte barroca es diferente de la que Castiglione idealizó.

${ }^{23}$ Ver Maria Teresa Ricci, Du "cortesano" au "discreto": l'bomme accompli chez Castiglione et Gracián. Pour une contribution à l'histoire de l'honnête homme (Paris-Genève: H. Champion-Slatkine, 2009). También José Martínez Millán, "La Corte del Barroco. Cambios culturales y de comportamiento", en La corte del Barroco. Textos literarios, avisos, manuales de corte, etiqueta y oratoria, coord. Antonio Rey Hazas, Mariano de la Campa Gutiérrez y Esther Jiménez Pablo (Madrid: Polifemo, 2016), 7-25, especialmente 17-25.

${ }^{24}$ Ver Mercedes Blanco y Riva Evstifeeva, "Un sujet de Louis XIV à l'école de Tacite et de Gracián. La carrière littéraire d'Amelot de la Houssaie (1634-1706) au travers d'un examen critique des données biographiques et bibliographiques", e-Spania 35 (février 2020). Y Roger Chartier, "El proceso civilizatorio. Elias, Gracián, Amelot”, Co-herencia 11, 21 (julio-diciembre 2014): 13-24.

25 Ver Jesús Gascón, "Cortesanos, cronistas y poetas. Los escritos políticos de los hermanos Argensola en su contexto histórico", en Campo y campesinos en la España Moderna. culturas políticas en el mundo hispano, ed. M. ${ }^{a}$ J. Pérez Álvarez, Laureano M. Rubio Pérez, Alfredo Martín García, Madrid: Fundación Española de Historia Moderna, 2012), 1687-1696; y Lía Schwartz, "Góngora y Quevedo entre 1603 y 1627: literatos y cortesanos", en La corte del Barroco. Textos literarios, avisos, manuales de corte, etiqueta y oratoria, coord. Antonio Rey Hazas, Mariano de la Campa Gutiérrez y Esther Jiménez Pablo (Madrid: Polifemo, 2016), 517-542.

26 Ver el clásico estudio de Juan Manuel Rozas, "Lope contra Pellicer. Historia de una guerra literaria”, en La literatura en Aragón, Aurora Egido ed. (Zaragoza: Caja de Ahorros, 1984), 69-99; e Ignacio Arellano, "Costumbrismo cortesano y costumbrismo doméstico en dos sonetos de Lope (Rimas de Tomé de Burguillos)", Iberorromania 69-70, 1 (2011): 49-60.

${ }^{27}$ Muchas de ellas son de Salas Barbadillo, como he señalado en la "Presentación" de Géneros híbridos y libros mixtos en el Siglo de Oro, coord. $\mathrm{M}^{a}$ S. Arredondo, Mélanges de la Casa de Velárquez 43-2 (2013): 916, especialmente, p. 11. Ver también Manuel Fernández Nieto, "Entre costumbrismo y novela: Antonio Liñán y Verdugo y Baltasar Mateo Velázquez”, en ibidem, 53-67. Y David González Ramírez, 
continuación, partiendo de la edición príncipe, la más breve ${ }^{28}$, publicada en 1658, dedicada a don Fernando de Fonseca Ruiz de Contreras, Marqués de Lapilla, secretario del Consejo de Estado y de Despacho, considerado una de las hechuras del CondeDuque y personaje muy influyente hasta su muerte en 1660. La primera peculiaridad de este libro es que creció con diferentes adiciones en las ediciones de 1669, 1675 y la póstuma de 1698, y con distintos dedicatarios, todos ellos grandes cortesanos ${ }^{29}$, mientras esa Corte de Madrid cambiaba de rey, que era Felipe IV en 1658, y Carlos II en las siguientes ediciones.

Desde la portada se percibe la singularidad de la obra, pues se declara la excelencia y exclusividad de Madrid como Corte, frente a las demás del orbe; se califica su contenido: libro histórico-político; y se anuncia un doble propósito: en la primera parte se detallan y elogian las ventajas de Madrid, y en las tres partes siguientes, dedicadas al «cortesano en Madrid», se le instruye «con dogmas cristianamente políticos, para adorno del entendimiento, aliño de la voluntad y perfección de la memoria» (p.411).

La primera de las cuatro partes, la más convencional y descriptiva, es un elogio de la Corte de Madrid, que se equipara a la de Salomón en la Aprobación de don Gaspar de Seijas. Se trata de una hipérbole habitual en la época: por ejemplo, Remiro de Navarra, autor de Los Peligros de Madrid, opinaba en 1646 que Madrid era «la capital del orbe» (p. 184). Dicha Aprobación adelantaba que el propósito del libro era una «grande empresa», bien lograda por el cronista Núñez de Castro. Sin embargo, llama la atención que asocie a Corte tan magnífica un contexto negativo, como indican las expresiones: «antídotos en el mismo veneno», «Tranquilidad en la tempestad»y «Bonanza en los escollos». Como las partes II, III y IV intentan «componer a un cortesano para que entre lo peligroso de la Corte se conserve sin despeños» (p. 413), la Aprobación señala el mérito del cronista, encadenando las siguientes preguntas retóricas: «¿Qué ponzoña contra las virtudes no reina en las cortes? ¿qué borrascas contra la modestia, qué bajíos contra el buen proceder y qué despeños contra el acertado dictamen no tienen vigoroso imperio en las patrias comunes?» (p. 414). Se concluye entonces que «ajustar a un cortesano» para que, efectivamente, lo sea «...grande realce es del juicio que lo fabrica y de la pluma que lo da a la estampa» (p. 414).

En el Prólogo al lector el primer párrafo es una verdadera andanada contra los nobles que dan mal ejemplo. El autor afirma lo engañoso de algunos cortesanos,

"Literatura cortesana y narrativa en el Siglo de Oro: de Castiglione a Salas Barbadillo", en M. Albert, L. Coppola y V. Aranda, coord. La narrativa de Salas Barbadillo (Peter Lang: Frankfurt am Main, 2020), 1541.

${ }^{28}$ Cito por la edición de Enrique Suárez Figaredo, LEMIR 19 (2015), 409-582.

${ }^{29}$ En la edición de 1669 el autor se dirige a don Antonio Fernández de Castro, caballero de Santiago y Alcalde Mayor de Burgos, presentándole como prototipo del cortesano: noble, sabio, afable, generoso, discreto, etc.: cortesano, en suma. En la de 1675, se dirige al poderoso don Fernando Valenzuela, caballero de Santiago, caballerizo y valido de la Reina; además, según nuestro autor, ejemplo práctico de cortesano: así lo propone para que sus lectores aprendan la teoría "especulativa" en las normas de su libro, y la práctica en la persona del mecenas. Finalmente, en la edición póstuma de Barcelona, 1698, el libro se dedica a don Francisco María Pascual, quinto conde de Cervellón. 
empezando por los de origen noble, que traicionan sus principios: «los cortesanos en el origen [son] nobles, [pero] en el obrar [parecen] pecheros, en la cuna [son] augustos y [parecen] plebeyos en las acciones...» (p. 421). Y lamenta que haya «entendimientos tan ciegos que... juzguen que el ser cortesano es tácita licencia para los desórdenes y privilegio a nuevos desmanes.» (p. 421).

En el mismo Prólogo el autor declara la desigual estructura del libro, porque la primera parte se basa en trabajos anteriores, que no precisa, pero que se remontan a Gil González Dávila y su Teatro de las grandezas de Madrid (1623), como ya se ha señalado ${ }^{30}$. El autor explica que no ha querido causar fatiga al lector, para que se dedique a los tres libros siguientes «en que se ha esmerado más mi cuidado»:

Para el primer libro, que trata de las ventajas de Madrid a otras cortes, había juntado trabajos de algunos años, y pareciéndome después tarea poco lucida, en que se mostraba más el afán que el ingenio, entresaqué algunas noticias, dejando sin fastidio al Lector para los tres libros siguientes, en que se ha esmerado más mi cuidado. (p. 421).

Y afirma que para ello escribió los «dogmas políticos», «que son proposiciones que establezco», todas basadas en lugares sagrados, es decir, autoridades bien reconocidas: el Espíritu Santo y los «Padres e Intérpretes», no en sus propias capacidades y estudios (p. 421). En efecto, por las dedicatorias de las dos ediciones posteriores, comprobamos que el autor se siente satisfecho de la acogida de lo que él llama «mi cortesano», concediendo especial relevancia a esta parte de la obra.

El libro lleva un Índice largo y muy detallado, tanto en la parte dedicada a las ventajas de Madrid sobre otras cortes, como en las tres siguientes, que se refieren a los consejos y máximas para el cortesano. Desde ese Índice se percibe la desigual estructura y extensión de las partes:

La Primera parte (I) consta de 8 capítulos (llegan a 14 en la edición de 1698, con muchas adiciones), desde la etimología de corte, a la población, calles, plazas, huertas, abastecimientos de Madrid, etc. Dedica un capítulo al ocio, con alabanza a los autores dramáticos y sus representaciones. Y se refiere a las cortes con quien Madrid no quiere competencia, especialmente Roma, con sus templos y palacios, que se detiene en alabar; y para argumentar la supremacía de Madrid se apoya en la grandeza del príncipe y su valor espiritual, y también en el gobierno secular, con los Consejos y Tribunales de Madrid. Como ya se ha estudiado, esta parte del libro es de mucho interés por la infinidad de datos sobre «las dignidades, oficios, pensiones y

${ }^{30}$ Ver Carmen Peraita, "Teatro tipográfico, libro de espacios cortesanos. Teatro de las grandezas de Madrid, de Gil González Dávila”, en La fractura historiográfica. Las investigaciones de Edad Media y Renacimiento desde el Tercer Milenio, Javier San José Lera, Francisco Javier Burguillo López, y Laura Mier Pérez, coord. (Salamanca: Semyr, 2008), 705-722, que indica acertadamente cómo la obra de González Dávila contribuye a "la forja de Madrid como espacio urbano cortesano..." (705), y lo mucho que le deben Jerónimo de la Quintana y Núñez de Castro. 
mercedes... $\rangle^{31}$ que son concedidos por el Rey y que atraían a los pretendientes. Al ser cargos que emanan del poder del Rey, se relacionan con la Corte de Madrid.

La Segunda parte (II), titulada «Instrucciones al cortesano», consta de 10 dogmas, y tácitamente indica que es la dedicada al entendimiento, empezando por los vicios que el cortesano debe huir, y los conocimientos que ha de aprender. Sorprende gratamente el largo epígrafe dedicado a la música; y en contraste la escasez de aprendizaje de la filosofía - «Sepa, pues, de la Filosofía lo preciso para que se diga que no la ignora» (p. 493)- y de la teología: «En las noticias teológicas, más quisiera a los caballeros cortesanos, preciarse de discípulos obedientes que de maestros presumidos» (p. 493).

La Tercera parte, o Libro III, titulada «De la voluntad», es la más extensa. Consta de 12 dogmas, más 5 proposiciones, más varias cuestiones y un Apéndice. Es la parte más costumbrista, porque el autor se detiene en cuestiones prácticas, casi domésticas, y su tono resulta si no ameno, menos sermoneador que el resto.

Por ejemplo, en el dogma III, destacan las virtudes que el cortesano ha de ejercitar: cortesía, religión, amor a la verdad. En el dogma V, sobre el porte que ha de tener con su esposa (p. 507), el autor sigue el libro de los Proverbios de Salomón, porque «el intento de Salomón, en el libro de sus Proverbios, sea guiar a un mancebo en los rumbos, nunca sendereados sin peligro de la Corte...» $\mathrm{Y}$ «... entre los jóvenes cortesanos, los menos pueden aspirar a la continencia, por ser un bien que vive muy arriesgado a los desmanes licenciosos de la torpeza.». Todo este dogma es un canto a las bondades y beneficios del matrimonio, porque contra «Los ardores del apetito, ...en los cristales de la mujer propia hallan refrigerio» (p. 507); además de que «Los hijos en la mujer propia son la paz y el vínculo de nuevos amores entre los casados» (p. 509).

El dogma VI se refiere la educación de los hijos. El dogma VII a la elección de los amigos (p. 518). El dogma VIII está dedicado a la elección de los criados (p. 523), asunto delicado, según piensa el autor, cuya dificultad se enuncia con la siguiente frase lapidaria que abre este epígrafe: «la muerte y la servidumbre son hijos de un padre» (p. $523)$.

El dogma IX, sobre los trajes y los aliños del cortesano (p.531), se inicia con una declaración taxativa: el traje «de pies a cabeza le manifiesta todos los afectos del alma y tanto cuanto en lo exterior le viste, en lo interior le desnuda. A Julio César le dio que pensar, y que temer, un mozo desaliñado en el vestido, poco cuidadoso en la melena...» (p. 531). En esta cuestión de la vestimenta y el adorno, el autor defiende siempre un término medio, huyendo de la afectación. A ella se dedica el dogma X: "Cómo no solo en el aliño, sino en todas las demostraciones, le importará para el crédito huir la afectación”. Los excesos al respecto se satirizan en la época, por ejemplo,

31 Ver Francisco Chacón Jiménez y Nuno G. Monteiro, Poder y movilidad social: cortesanos, religiosos y oligarquias en la peninsula ibérica, ss. XV-XIX (Madrid: CSIC, 2006), 134. Y Martínez Millán, "La corte del barroco. Cambios culturales y de comportamiento", en La corte del Barroco. Textos literarios, avisos, manuales de corte, etiqueta y oratoria (Madrid: Polifemo, 2016), 17, donde se ocupa del libro de Alonso Núñez de Castro, señalando que la primera parte aporta luz sobre el funcionamiento de la corte, los oficios, los consejos, etc. 
en las «figuras» de la Vida de Corte de Quevedo ${ }^{32}$, y se censuran por los costumbristas como Zabaleta ${ }^{33}$.

A la moderación en comida y bebida se refiere el dogma XI, afirmando: «lo cortesano es prenda que se sobrepone a lo racional: no puede ser buen cortesano el que no tuviere con perfección el ser hombre, y los que tienen todo su dios en la comida y bebida casi dejan de ser hombres y pasan a ser troncos». (p. 538).

El dogma XII, sobre el duelo, ha concitado la atención de los estudiosos por su mucha información. Consta de cinco proposiciones sobre casuísticas concretas, que inculpan o exculpan a los duelistas ${ }^{34}$, y va seguido de un Apéndice sobre los padrinos del duelo. El habitual tono dogmático, nunca mejor dicho, se sustituye por un tono coloquial en la proposición $4^{\mathrm{a}}$, donde aparece un quídam, un tal «Pedro, desafiado...», que sigue en la $5^{\mathrm{a}}$, con un «Pedro, noble...», y en donde se halla al final un tal Juan, pronto a reñir con Pedro, tras el siguiente argumento, que termina en una especie de trabalenguas, bastante confuso: «Lo sexto: nadie dirá que después de haber reñido igualmente el desafiado con el que desafía queda agraviado el que admitió el combate; luego en desafiarle no le agraviaron.»(p. 555.). En general, tantos argumentos y justificaciones no aclaran, sino que confunden cada uno de los casos, expuestos con una frase larga y premiosa, y en ocasiones alguna proposición matiza o contradice lo que antes afirmaba. Así en la proposición 4a:

Consta de lo dicho que toda especie de duelo debe reprobarse como introducción del Demonio» (p. 552); y en la proposición $5^{\text {a }}$ : «Dije que [...] a título de desvanecer el delito no podía [...]. Ahora digo de defender la vida, si es medio único el certamen singular, puede admitirle (p. 553).

El libro IV, sobre las perfecciones de la memoria ${ }^{35}$, consta de 7 dogmas, con una interesante declaración en el primer párrafo, que en cierto modo justifica la aparente desorganización estructural de las tres partes dedicadas a la formación de ese cortesano:

Es la memoria un aliño tan esencial a las naturalezas entendidas, que lo acierta quien aun en rigor filosófico la equivoca con la perfección del entendimiento. Aun entre los

32 Para las figuras lindas y figuras artificiales, ver Francisco de Quevedo, Prosa satírica ed. Ignacio Arellano (Barcelona: Debolsillo, 2003), 87-88.

${ }^{33}$ Ver la descripción de un galán que hace Juan de Zabaleta, El día de fiesta por la mañana y por la tarde, ed. Cristóbal Cuevas (Madrid: Castalia, 1983), 99-113, especialmente p. 99 sobre la limpieza y los perfumes: "La limpieza es precisa, los perfumes son escusados", y p. 104 sobre el cabello: el barbero "Desenvaina un peine y unas tijeras [...] anda de aquí para allí despuntando pelos".

34 Así lo señaló Claude Chauchadis, "Libro y leyes del duelo en el Siglo de Oro", Criticón 39 (1987): 77-113, donde afirma: "La ambigüedad de las leyes del duelo y la vacilación de los moralistas ante la actitud que tomar frente a ellas son sin duda elementos que favorecen su penetración y su extensión en España. En el siglo XVII se manifiestan consejeros del duelo que más tienen que ver con el ámbito cortesano que con los círculos militares" (p. 95).

35 Marcelo Luzzi Traficante ha destacado el papel que nuestro autor concede a la memoria en "Memoria y corte en la España de Carlos II", Tiempos modernos, 8, 31 (2015). 
que distinguen las potencias del alma tiene patronos este sentir, y dicen que una misma potencia, cuando discurre es entendimiento; cuando se acuerda de lo que discurrió, memoria. (p. 559)

Núñez de Castro defiende la excelencia de esta potencia, porque es útil y necesaria, aunque reconoce: «Ya sé que han satirizado muchos contra sus traiciones llamándola potencia villana...». Recomienda medios para perfeccionarla, y aconseja recordar los dichos y hechos de príncipes, pero olvidar los «ajenos defectos» y olvidarse de sí mismo y de cualquier arrogancia (p. 573).

En el dogma último, el $7^{\circ}$, titulado «La memoria de los beneficios que recibe, y el olvido de los que hace, son adorno de mucho lustre en el cortesano» (p. 579), el autor insiste en que hay que recordar los beneficios recibidos y a los bienhechores. Este último dogma, además de recomendaciones pragmáticas, posee un componente moral sobre la gratitud, cualidad muy necesaria para el cortesano, que tanto recibe de los príncipes: «rústico le hace al hombre lo desatento a su bienhechor, y cortesano lo memorioso en materia de beneficios» (p. 580). El autor, siguiendo a Séneca en una hermosa metáfora sobre la «tierra silvestre» y la «tierra cultivada», afirma que el cortesano se distingue del rústico en la demostración de gratitud: «... la tierra silvestre convierte en espinas o en herbaje inútil la semilla que le encomiendan, pero la tierra cultivada agradece con las usuras el beneficio». (p. 580)

En general, los vicios y las virtudes que el autor tiene en cuenta son los habituales en la prosa didáctica del siglo XVII, nada que sea específico para el cortesano en Madrid, salvo en fragmentos muy concretos al final del libro, relativos a la memoria y su relación con la prudencia y el conocimiento de las reglas: «Destos ritos con que las majestades humanas quieren ser veneradas digo que debe hacer frecuente memoria el cortesano porque en la verdad el forastero de Madrid noticioso dellas en cualquiera conversación pasará por serlo y al de la Corte, si le faltan le mirarán como a forastero [...] No son pocos los que en Madrid, sin tener más alhajas de entendimiento ni más papeles $[\ldots]$ que las advertencias de las etiquetas de Palacio $[\ldots]$ tienen aun entre los bien entendidos granjeada opinión de sabios...». (pp. 569-570). Por ello se echa de menos un resumen unificador tras las muchas advertencias inconexas, a excepción del vínculo ya citado que el autor establece entre las tres partes (o libros) y las tres potencias del alma: entendimiento, voluntad y memoria.

En cuanto al estilo, tanto los capítulos de la primera parte, como los dogmas y las proposiciones de las tres siguientes, se expresan con una sintaxis barroca tendente a la antítesis y al hipérbaton, que contrasta con afirmaciones lacónicas. Para dar brillo y peso a sus afirmaciones, Núñez de Castro, igual que tantos escritores del siglo XVI, se apoya en buen número de autoridades, no solo la Biblia y los Santos Padres de la Iglesia, sino filósofos, historiadores, emperadores, etc., y entre ellos especialmente: Platón, Aristóteles, Quintiliano, Julio César, Plutarco y Séneca.

Como el autor había anunciado, estos nombres ilustres contribuyen a su propósito de «mayor cuidado», y a la suma del «afán» de la primera parte y del «ingenio» de la segunda, en el intento de formar a un cortesano de su tiempo («de honrado trato», 
como decía Covarrubias) para esa corte única de Madrid («solo Madrid es corte») que había descrito al comienzo de la obra.

En conclusión, la evolución desde el cortesano renacentista idealizado por Castiglione-Boscán hasta este cortesano madrileño de la segunda mitad del XVII muestra las posibilidades del tipo literario, según las diferencias genéricas: un refinado diálogo italiano a varias voces, o esta especie de tratado o manual en el que prima lo didáctico frente al entretenimiento. El itinerario recorrido muestra que los muchos forasteros e incautos que llegan a Madrid viven, o sobreviven, avisados y entretenidos con la guía de Liñán y Verdugo; y que intentan instalarse en una corte que es peligrosa, según Remiro de Navarra, o de costumbres vanas y poco ejemplares, según Zabaleta. Pero es, también, una corte tan única como la pinta detalladamente Núñez de Castro en la primera parte de su obra, ya que puede acoger a quienes sigan los dogmas (prácticos, eruditos y políticos) de la segunda: El cortesano en Madrid. 


\section{REFERENCIAS BIBLIOGRÁFICAS}

Academia burlesca que se bizo en Buen Retiro a la Majestad de Filipo IV el Grande año de 1637, edición de Ma Teresa Julio (Madrid: Iberoamericana Vervuert, 2007).

Álvarez Ossorio, Antonio. "Corte y cortesanos en la Monarquía de España”, en G. Patrizi y Amedeo Quondam, eds., Educare il corpo, educare la parola. Nella tratatistica del Rinascimento (Roma: Bulzoni, 1998), 297-365.

Anfiteatro de Felipe el Grande, edición de Antonio Pérez Gómez (Cieza: Ediciones Conmemorativas, 1974).

Arellano, Ignacio. "La picaresca menor: un itinerario complejo", Ínsula 503 (1988): 2.

- "Costumbrismo cortesano y costumbrismo doméstico en dos sonetos de Lope (Rimas de Tomé de Burguillos)", Iberorromania 69-70, 1 (2011): 49-60. https://doi. org/10.1515/iber.2009.005

Arredondo, M. ${ }^{a}$ Soledad, "Avisos sobre la capital del orbe en 1646: Los Peligros de Madrid”, Criticón 63 (1995): 89-101.

—, "De la picaresca menor al "costumbrismo": la Guía y avisos de forasteros... y otros escarmientos", Edad de Oro XX (2001): 9-21.

-, "El engaño cortesano en los relatos de la Guía y avisos de forasteros que vienen a la corte, de Liñán y Verdugo", en Siglos dorados. Homenaje a Augustin Redondo I, coord. Pierre Civil, 67-82. (Madrid: Castalia, 2004).

—, "Presentación" de Géneros híbridos y libros mixtos en el Siglo de Oro, coord. Ma S. Arredondo, Mélanges de la Casa de Velárquez. 43-2 (2013): 9-16. https://doi.org $\angle 10.4000 / \mathrm{mcv} .5103$

-, "De La Gitanilla a La sabia Flora malsabidilla. El género, el personaje y el matrimonio", Edad de Oro XXXIII (2014): 163-177. https://doi.org/10.15366 Ledadoro2014.33.010

—, "Diálogo, diario, historia, juicio, dictamen: géneros y estilo en la prosa política de Juan de Palafox y Mendoza", Revista Internacional d'Humanitats (30 jan 2014).

-, "María Teresa de Austria y la Paz de los Pirineos", en Mujeres en la Corte de los Austrias. Una red social, cultural, religiosa y politica, ed. M. ${ }^{a}$ Leticia Sánchez Hernández (Madrid: Polifemo, 2019), 450-478. 
—, "Juan de Palafox y Mendoza: la vida de un consejero, obispo, virrey... y escritor" en De la vida a la fantasía, en prensa.

—, "Una relación total: el viaje, las fiestas, la boda y la Paz de los Pirineos en el Viaje del rey nuestro señor don Felipe IV a la frontera de Francia (1667), de Leonardo del Castillo", en Homenaje a Jean-Pierre Etienvre, en prensa.

Benigno, Francesco. "Corte y anti-corte en la literatura política barroca", en La corte del Barroco. Textos literarios, avisos, manuales de corte, etiqueta y oratoria, ed. Antonio Rey Hazas, Mariano de la Campa Gutiérrez y Esther Jiménez Pablo (Madrid: Polifemo, 2016), 27-52.

Blanco, Mercedes. "Un monumento poético en torno a la imagen de Felipe IV: el Anfiteatro de Felipe el Grande", en Los poderes de la imagen (Lille: Université de Lille 3, 1998), 107-114.

Blanco, Mercedes y Evstifeeva, Riva. "Un sujet de Louis XIV à l'école de Tacite et de Gracián. La carrière littéraire d'Amelot de la Houssaie (1634-1706) au travers d'un examen critique des données biographiques et bibliographiques", e-Spania 35 (février 2020). https://doi.org/10.4000/e-spania.34436

Caro de Mallén, Ana. Contexto de las Reales Fiestas que se bicieron en el palacio del Buen Retiro (1637), edición de Antonio Pérez Gómez (Valencia: Tipografía Moderna, 1951).

Correa Calderón, Evaristo. Costumbristas españoles), vol. I. (Madrid: Aguilar, 1950).

Chacón Jiménez, Francisco y Monteiro, Nuno G. Poder y movilidad social: cortesanos, religiosos y oligarquias en la peninsula ibérica siglos XV-XIX (Madrid: CSIC, 2006).

Chartier, Roger. "El proceso civilizatorio. Elias, Gracián, Amelot", Co-herencia 11, 21 (julio-diciembre 2014): 13-24 https://doi.org/10.17230/co-herencia.11.21.1

Chauchadis, Claude. "Libro y leyes del duelo en el Siglo de Oro", Criticón 39 (1987): 77-113.

Díez de Revenga, Francisco Javier. "Saavedra Fajardo en el Anfiteatro de Felipe el Grande", Monteagudo 86 (1984): 69-7.

Fernández Gracia, Ricardo. "Una corte itinerante por tierras europeas 1629-1631. De Madrid a Viena con la infanta doña María, bajo la mirada de don Juan de Palafox", en Visiones de un imperio en fiesta, dir. Inmaculada Rodríguez Moya y Víctor Mínguez Cornelles, 309-339. (Madrid: Fundación Carlos de Amberes, 2016). 
Fernández Nieto, Manuel. "Entre costumbrismo y novela: Antonio Liñán y Verdugo y Baltasar Mateo Velázquez”, en $\mathrm{M}^{\mathrm{a}} \mathrm{S}$. Arredondo, coord. Mélanges de la Casa de Velázquez 43-2 (2013): 53-67. https://doi.org/10.4000/mcv.5139

García Bernal, José Jaime. "De Felipe el Grande al Rey Pacífico. Discursos festivos y funerales durante el reinado de Felipe IV", Obradoiro de Historia Moderna 20 (2011): 73-104. https://doi.org/10.15304/ohm.20.8

García Santo Tomás, Enrique. Espacio urbano y creación literaria en el Madrid de Felipe IV. (Madrid: Universidad de Navarra/Iberoamericana/Vervuert, 2004). https://d oi.org/10.31819/9783865279439

Gascón, Jesús. "Cortesanos, cronistas y poetas. Los escritos políticos de los hermanos Argensola en su contexto histórico." En Campo y campesinos en la España Moderna. culturas politicas en el mundo hispano, $\mathrm{M}^{\mathrm{a}} \mathrm{J}$. Pérez Álvarez, Laureano M. Rubio Pérez, Alfredo Martín García, eds., 1687-1696. (Madrid: Fundación Española de Historia Moderna, 2012).

González de Amezúa, Agustín. Formación y elementos de la novela cortesana. Madrid: Tipografía de Archivos, 1929.

González Ramírez, David. "Literatura cortesana y narrativa en el Siglo de Oro: de Castiglione a Salas Barbadillo." En La narrativa de Salas Barbadillo, coord. M. Albert, L. Coppola y V. Aranda, 15-41 (Peter Lang: Frankfurt am Main, 2020).

—, "La disolución del marco narrativo en el origen del costumbrismo. De la Guía y avisos de forasteros a los días de fiesta de Zabaleta", Cuadernos de Filología Italiana volumen extraordinario (2010): 81-94.

González de Rosende, Antonio. Vida del Ilustrísimo y excelentísimo señor Don Juan de Palafox y Mendoza, en Obras completas. Tomo XIII, libro I. (Madrid: Imprenta de Gabriel Ramírez, 1762)

La vida de Lazarillo de Tormes y de sus fortunas y adversidades, ed. Alberto Blecua, (Madrid: Castalia, 1983).

Lázaro Carreter, Fernando. "El oficio real" en Lazarillo de Tormes en la picaresca (Barcelona: Ariel, 1983), 16-171.

Luzzi Traficante, Marcelo, "Memoria y corte en la España de Carlos II", Tiempos modernos, 8, 31 (2015).

Maravall, José Antonio. La cultura del Barroco (Barcelona: Ariel, 1986). 
Martínez Millán, José. “La corte de la Monarquía Hispánica”. Studia historica 28 (2006): 17-61.

—, "La Corte del Barroco. Cambios culturales y de comportamiento", en La Corte del Barroco. Textos literarios, avisos, manuales de corte, etiqueta y oratoria, coord. Antonio Rey Hazas, Mariano de la Campa Gutiérrez y Esther Gómez Pablos, 7-25 (Madrid: Polifemo, 2016).

Muñoz Sánchez, Juan Ramón. "La Corte, del mundo maravilla: la picaresca durante el reinado de Felipe IV”, NRFH LXII, 2 (2014): 383-480. https://doi.org/10.2 $\underline{4201 / \text { nrfh.v62i } 2.1148}$

Núñez de Castro, Alonso. Libro histórico político. Solo Madrid es corte y El cortesano en Madrid, edición de Enrique Suárez Figaredo, LEMIR 19 (2015), 409-582.

Orobitg, Christine. "Anécdota cinegética y construcción del personaje histórico en el Anfiteatro de Felipe IV el Grande (1631), de José Pellicer". En El hombre histórico y su puesta en discurso en el Siglo de Oro, eds. José Enrique Duarte e Isabel Ibáñez, 139-15 (New York: Idea, 2015).

Peraita, Carmen, "Apacible brevedad de los renglones, abreviada vida de monarcas: Ana de Castro Egas, Francisco de Quevedo y la escritura del panegírico regio". La Perinola 9 (2005): 151-170.

-, "Teatro tipográfico, libro de espacios cortesanos. Teatro de las grandezas de Madrid, de Gil González Dávila", en La fractura historiográfica. Las investigaciones de Edad Media y Renacimiento desde el Tercer Milenio, coord. Javier San José Lera, Francisco Javier Burguillo López, y Laura Mier Pérez, 705-722. (Salamanca: Semyr, 2008).

Pellicer de Tovar, José. Avisos I, ed. Jean-Claude Chevalier y Lucien Claire. (Paris: Éditions Hispaniques, 2002).

Quevedo, Francisco de, Prosa satírica, ed. Ignacio Arellano (Barcelona: Debolsillo, 2003).

Quondam, Amedeo. "Introducción" a la edición de El Cortesano. (Milan: Garzanti, 1987).

—, El discurso cortesano. Edición e introducción de Eduardo Torres Corominas. Madrid: Polifemo, 2013.

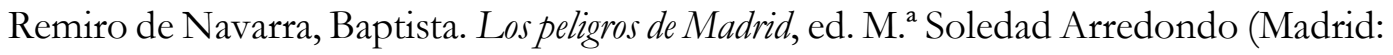
Castalia /Comunidad de Madrid, 1996). 
Ricci, Maria Teresa. Du "cortegiano" au "discreto": l'homme accompli chez Castiglione et Gracian. Pour une contribution à l'bistoire de l'bonnête homme. (Paris-Genève: H. ChampionSlatkine, 2009).

Rozas, Juan Manuel. "Lope contra Pellicer. Historia de una guerra literaria", en La literatura en Aragón, ed. Aurora Egido, 69-99 (Zaragoza: Caja de Ahorros, 1984).

Ruiz, Pedro. "Corta / cortesana. Apuntes a propósito de una denominación problemática para la narrativa barroca". Lejana. Revista crítica de narrativa breve 7 (2014): 1-13.

Schwartz, Lía. "Góngora y Quevedo entre 1603 y 1627: literatos y cortesanos”, en La corte del Barroco. Textos literarios, avisos, manuales de corte, etiqueta y oratoria, coord. Antonio Rey Hazas, Mariano de la Campa y Esther Gómez Pablos, 517-542 (Madrid: Polifemo, 2016).

Sevilla, Florencio, "Presentación” a su edición de La novela picaresca española (Madrid: Castalia, 2001).

Zabaleta, Juan de, El día de fiesta por la mañana y por la tarde, ed. Cristóbal Cuevas García (Madrid: Castalia, 1983).

Recibido: 5 de mayo de 2021

Aceptado: 31 de julio de 2021 